\title{
Pregnancy outcomes after treatment for preinvasive cervical lesions
}

\author{
(®) $(\Theta)$ OPEN ACCESS \\ New analyses will help women balance the effectiveness of treatment with the safety of future \\ pregnancies
}

\section{Ioannis Biliatis consultant gynaecologist/oncologist}

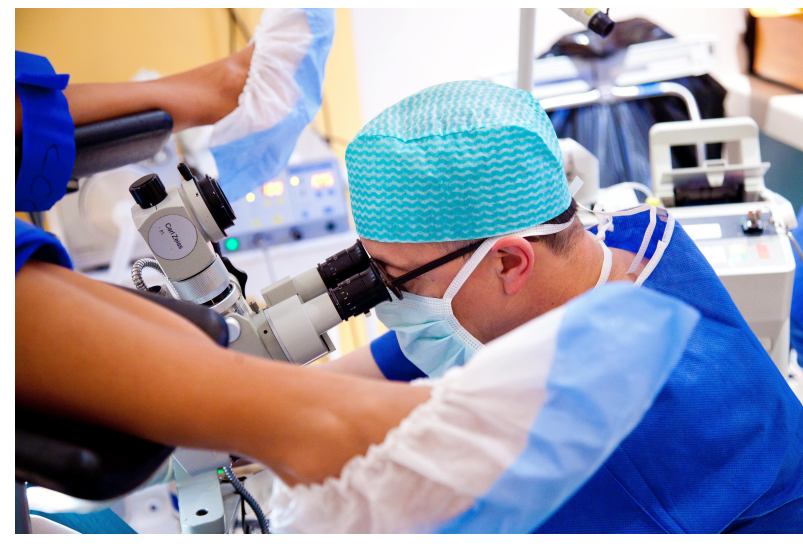

[Image: Phanie/Alamy]

The anatomy and histological structure of the uterine cervix are mainly responsible for providing the support needed to bring a pregnancy to term. Both characteristics can be significantly altered after surgical excision or ablation for the treatment of preinvasive or early invasive cervical lesions. Despite the documented effectiveness of these treatments ${ }^{1}$ they can potentially weaken the cervix, leading to preterm birth and all consequent adverse sequelae in the neonate. Young women of reproductive age presenting to the colposcopy clinics with preinvasive cervical lesions pose a challenge for clinicians. The treatment, usually with a cone biopsy, needs to be deep enough to prevent recurrence and provide oncological safety but shallow enough to provide subsequent obstetric safety. For years a debate on the best size and depth of the cone to satisfy both above conditions has left clinicians uncertain how radical they should be.

In a linked paper, Kyrgiou and colleagues (doi:10.1136/bmj. i3633) report a comprehensive meta-analysis of 71 studies, including 65000 treated and more than six million untreated women. ${ }^{2}$ Though theirs is not the first meta-analysis on this important topic, ${ }^{34}$ it is the first to report relative risks for treated versus untreated women regarding cone depth/volume, repeated treatments, and comparison group used.

The methods are sound, and studies were included only if they had a comparison group of untreated women. Untreated comparators were external, usually from a population based registry, or internal (pregnancies before treatment in the treated women). The authors also compared treated women with women who had preinvasive lesions and did not undergo treatment. Using different comparator groups, they were able to exploit their respective advantages and disadvantages, especially in relation to controlling for confounding. ${ }^{5}$ Findings from both main and subgroup analyses will help guide affected women and their clinicians.

Kyrgiou and colleagues found that the risk of preterm birth $(<37$ weeks' gestation) is almost 1.8 times higher for treated women compared with untreated women when all treatment methods are considered (ablative and excisional). Specifically, the relative risk for large loop excision of the transformation zone (LLETZ) is 1.56 (95\% confidence interval 1.36 to 1.79 ), increasing to 2.7 (2.14 to 3.40) after cold knife conisation. In addition, repeat treatments were associated with a higher risk of preterm birth than single treatments. This trend was the same for all excisional techniques (the relative risks for one $v$ two LLETZ were 1.74 $v 2.81)$. Furthermore, the depth of the cone was positively and progressively linked with the relative risk for preterm birth. Cones deeper than $20 \mathrm{~mm}$ increased the risk almost fivefold relative to untreated women (relative risk $4.91,95 \%$ confidence interval 2.06 to 11.68 ), while this risk was only slightly raised after smaller cones (for example, with cones $\leq 10-12 \mathrm{~mm}$ the relative risk was $1.54,1.09$ to 2.18 ). These findings show clearly that increasing the radicality of treatment (deep cones, repeat treatments) has a consistent adverse effect on risk of preterm birth, as well as on the risk of adverse obstetric and neonatal outcomes.

The question of whether an excisional biopsy of the cervix is an independent factor that can cause preterm birth, or whether 
women can be predisposed to both preinvasive lesions and preterm birth from an underlying common factor (such as HPV infection) is not new. Kyrgiou and colleagues confirmed that untreated women with preinvasive lesions indeed have an increased risk of preterm birth compared with the general population. Subgroup analysis showed that cone biopsies less than $10 \mathrm{~mm}$ in depth did not increase the risk significantly, compared with these untreated women, although this was based on a small number of studies. For deeper cones, however, the additional adverse effect of the surgical intervention on the risk of preterm birth became much clearer.

All the findings of Kyrgiou and colleagues should be interpreted cautiously as their meta-analysis included mainly retrospective cohort studies with well known inherent flaws and biases. Some of the subgroup analyses were based on a small number of studies without enough power for firm conclusions. Finally, confounding probably inflated relative risks in the external population based comparisons. In analyses that used internal comparators to help control confounding, the relative risks were attenuated but remained significantly increased in most subgroup analyses.

This new meta-analysis adds to growing evidence that cervical treatment for preinvasive disease can lead to preterm birth and adverse neonatal outcomes. Women and their clinicians must navigate the difficult trade-off between oncological safety now and the safety of future pregnancies. Both can be reassured that a small excisional biopsy aiming to remove the lesion completely and prevent a second treatment most likely confers the best balance of outcomes, with only a small risk for preterm birth in a subsequent pregnancy.

Competing interests: I have read and understood the BMJ Group policy on declaration of interests and declare the following interests: none.

Provenance and peer review: Commissioned; not peer reviewed.

1 1Kocken M, Helmerhorst TJ, Berkhof J, et al. Risk of recurrent high-grade cervical intraepithelial neoplasia after successful treatment: a long-term multi-cohort study. Lancet Oncol 2011;12:441-50. doi:10.1016/S1470-2045(11)70078-Xpmid:21530398.

2 2Kyrgiou M, Athanasiou A, Paraskevaidis E, et al. Adverse obstetric outcomes after local treatment for cervical preinvasive and early invasive disease according to cone depth: systematic review and meta-analysis. BMJ 2016;354:i3633.

3 Kyrgiou M, Koliopoulos G, Martin-Hirsch P, Arbyn M, Prendiville W, Paraskevaidis E. Obstetric outcomes after conservative treatment for intraepithelial or early invasive cervical lesions: systematic review and meta-analysis. Lancet 2006;367:489-98. doi:10.1016/ S0140-6736(06)68181-6pmid:16473126.

4 Conner SN, Frey HA, Cahill AG, Macones GA, Colditz GA, Tuuli MG. Loop electrosurgical excision procedure and risk of preterm birth: a systematic review and meta-analysis. Obstet Gynecol 2014;123:752-61. doi:10.1097/AOG.0000000000000174pmid:24785601. 5 Bruinsma FJ, Quinn MA. The risk of preterm birth following treatment for precancerous changes in the cervix: a systematic review and meta-analysis. BJOG 2011;118:1031-41. doi:10.1111/j.1471-0528.2011.02944.xpmid:21449928.

Published by the BMJ Publishing Group Limited. For permission to use (where not already granted under a licence) please go to http://group.bmj.com/group/rights-licensing/ permissions

This is an Open Access article distributed in accordance with the Creative Commons Attribution Non Commercial (CC BY-NC 3.0) license, which permits others to distribute, remix, adapt, build upon this work non-commercially, and license their derivative works on different terms, provided the original work is properly cited and the use is non-commercial. See: http://creativecommons.org/licenses/by-nc/3.0/. 